\title{
THE DETERMINATION OF PORT FACILITIES MANAGEMENT FEE WITH GUARANTEED VOLUME USING OPTIONS PRICING MODEL
}

Kee-Kuo Chen

Associate Professor, Department of Shipping and Transportation Management, National Taiwan Ocean University, kkchen@mail.ntou.edu.tw

Follow this and additional works at: https://jmstt.ntou.edu.tw/journal

Part of the Business Commons

\section{Recommended Citation}

Chen, Kee-Kuo (2005) "THE DETERMINATION OF PORT FACILITIES MANAGEMENT FEE WITH GUARANTEED VOLUME USING OPTIONS PRICING MODEL," Journal of Marine Science and Technology. Vol. 13: Iss. 1, Article 7.

DOI: $10.51400 / 2709-6998.2104$

Available at: https://jmstt.ntou.edu.tw/journal/vol13/iss1/7

This Research Article is brought to you for free and open access by Journal of Marine Science and Technology. It has been accepted for inclusion in Journal of Marine Science and Technology by an authorized editor of Journal of Marine Science and Technology. 


\title{
THE DETERMINATION OF PORT FACILITIES MANAGEMENT FEE WITH GUARANTEED VOLUME USING OPTIONS PRICING MODEL
}

\author{
Kee-Kuo Chen
}

Key words: build-and-lease contract, guarantee volume, real options, blackscholes formula.

\section{ABSTRACT}

This paper proposes a procedure to calculate the port facilities management fee (MF) in a build-and-lease (BL) contract with guaranteed volume $(\mathrm{GV})$. The MF pricing problem exists in the contracts concluded by the lessees of port facilities and harbor bureaus for a long time. The problem is solved by analyzing the property of GV firstly, and then taking the real option approach to find the MF in BL contracts with GV. Finally, to demonstrate the method a real BL contract with GV is provided and its MF is calculated in this paper.

\section{INTRDUCTION}

Build-and-Lease (BL) is one of the most important approaches to operate the facilities by harbor bureaus under the port privatization policy in Taiwan.

Under the traditional leasing contracts, harbor bureaus constructed the facilities, and lessees pay annual rentals and the management fees (MF). These charges depend on what kind of facilities leased and how many volumes of traffic handled.

In the BL contracts, the harbor bureau rents a zone to the lessee and also allows the lessee to build and use necessary facilities in this zone during the contract period. The ownership of facilities constructed by the lessee, however, belongs to the harbor bureau. Instead of paying the construction cost of the facilities on lump sum basis, the harbor bureau exempts the lessee from paying the annual rental in the BL contract period. The length of such exemption is determined in such a way that all the construction costs be covered by the lessees. The length of an exemption usually is longer than 10 years because in the most cases the construction costs of port facilities are usually greater than 10 times of annual rentals.

Paper Submitted 02/17/04, Accepted 01/13/05. Author for Correspondence: Kee-Kuo Chen.E-mail:kkchen@mail.ntou.edu.tw.

*Associate Professor, Department of Shipping and Transportation Management, National Taiwan Ocean University.
In order to maintain the stability of annual revenue, harbor bureaus usually require that a yearly guarantee volume $(\mathrm{GV})$ be included in BL contracts. Therefore, the minimum amount of total MF a lessee has to pay in a year is equal to the GV multiplied by per unit MF stipulated in a particular contract in spite of the fact that the lessee's annual operation quantity might fall below the GV.

In view of the $\mathrm{GV}$, harbor bureaus usually give a MF discount as a reward to the lessees as long as the annual volume handled exceeds GV. But there exists no exact rule or formula to determine the MF discount. The MF discount was determined case by case in practice. As a result, there might be cases in which similar contracts might have significantly different discounts. The range of MFs in BL contracts signed by Keelung, Taichung and Kaohsiung harbor bureaus in the past decades are summarized in Table 1 [5, 6, 12]. If there were no $\mathrm{GV}$, MF for the same goods in the same harbor should be much similar. But, as shown in Table 1, there could be much differences between MFs in different BL contracts even they were signed by the same harbor bureau for the same cargoes handled. For example, MFs of container could have a difference of $20 \%$ of total annual lease payment in BL contracts signed by Keelung harbor bureau.

Inevitably, the differences have caused many disputes between harbor bureaus and lessees who paid higher MFs than others. As a result, the lessees used to call for a reasonable standard method to compute MF discount. Harbor bureaus are also eager to solve this problem.

In this paper Black-Scholes call option formula is applied to evaluate the value of $\mathrm{GV}$ engaged in a BL contract and then to derive a formula to determine the MF discount. This result can provide a consistent standard to calculate the MF discount for any level of GV.

This paper is organized into six sections. The nature of BL contract with GV will be analyzed in the next section. The reason that real option analysis (ROA) method is an appropriate approach to evaluate the value 
Table 1. A summary of the MFs range in Taiwan harbor bureaus

\begin{tabular}{|c|c|c|c|}
\hline Port & Cargoes & Min. MF & Max. MF \\
\hline \multirow[t]{7}{*}{ Keelung } & cement & $29 \mathrm{NT} /$ ton & $31 \mathrm{NT} /$ ton \\
\hline & liquid & $26 \mathrm{NT} /$ ton & $30 \mathrm{NT} /$ ton \\
\hline & general cargo & $15 \mathrm{NT} /$ ton & $40 \mathrm{NT} /$ ton \\
\hline & container & $\begin{array}{l}10 \% \text { of total annual } \\
\text { lease payment }\end{array}$ & $\begin{array}{l}30 \% \text { of total annual } \\
\text { lease payment }\end{array}$ \\
\hline & construction and & $10 \%$ of total annual & $30 \%$ of total annual \\
\hline & building & lease payment & lease payment \\
\hline & oil & $24 \mathrm{NT} /$ ton & \\
\hline \multirow[t]{8}{*}{ Taichung } & Cement & $20 \mathrm{NT} /$ ton & $23 \mathrm{NT} /$ ton \\
\hline & liquid & $21 \mathrm{NT} /$ ton & $23 \mathrm{NT} /$ ton \\
\hline & general cargo & $\begin{array}{l}15.7 \% \text { of handling } \\
\text { charge }\end{array}$ & $\begin{array}{l}18.2 \% \text { of handling } \\
\text { charge }\end{array}$ \\
\hline & container & $\begin{array}{l}\text { front yard }{ }^{\circ} \mathrm{G} 13 \% \text { 20\% of sum of handling charge } \\
\text { and equipment expense back yard: } 140 \mathrm{NT} / \text { container }\end{array}$ & \\
\hline & grain & $\begin{array}{l}12 \% \text { of operation } \\
\text { revenue }\end{array}$ & $\begin{array}{l}14 \% \text { of operation } \\
\text { revenue }\end{array}$ \\
\hline & coal (general) & $15 \mathrm{NT} /$ ton & \\
\hline & coal (TEC) & $26.16 \mathrm{NT} /$ ton & \\
\hline & oil & $17.66 \sim 30 \mathrm{NT} / \mathrm{m}^{2}$ or $10 \mathrm{NT} / \mathrm{ton}$ & \\
\hline \multirow[t]{9}{*}{ Kaohsiung } & cement & $22 \mathrm{NT} /$ ton & $35 \mathrm{NT} /$ ton \\
\hline & liquid & $2.1 \mathrm{NT} /$ ton & $61 \mathrm{NT} /$ ton \\
\hline & general cargo & $\begin{array}{l}2 \% \sim 4 \% \text { of operation } \\
\text { revenue }\end{array}$ & \\
\hline & container & $\begin{array}{l}10 \% \text { of total annual } \\
\text { lease payment }\end{array}$ & \\
\hline & grain & $\begin{array}{l}10 \% \text { of total annual } \\
\text { lease payment }\end{array}$ & \\
\hline & construction and & $10 \%$ of total annual & \\
\hline & building & lease payment & \\
\hline & oil & $11 \mathrm{NT} /$ ton & \\
\hline & iron & $4.3 \mathrm{NT} /$ ton & \\
\hline
\end{tabular}

Source: Statistical Abstracts 2003 of Keelung, Taichung, and Kaohsiung [5, 6, 12].

of GV will be illustrated in Section 3. In Section 4, a formula to determine the MF discount in a BL contract with a particular level of GV will be derived. Finally, a real case will be studied using the formula derived from this paper. The last section gives a brief conclusion of the present study.

\section{THE NATURE OF BL CONTRACT WITH GV}

Under the traditional contract, harbor bureau might invest by itself, say, $C_{0}$, to build the necessary facilities for leasing. Assuming that there is no technology advantage to lessee to build the facilities, the lessee also has to spend $C_{0}$ to build them. Hence, we can assume that, in a BL contract, the present value of the sum of annual rentals paid by the lessee to the harbor bureau must also be $C_{0}$. Otherwise the contract should not be concluded.

Let $R_{t}$ be the total rental of year $\mathrm{t}$ under a $\mathrm{BL}$ contract. It is also assumed that $R_{t}$ is also the harbor bureau's annual amortization of facilities construction cost. Moreover, let $r$ be the cost of capital of the lessee. Under the assumption of value maximization objective of harbor bureau [9], the BL contract period, $T$, can be determined by the following equation:

$$
C_{0}=\sum_{t=1}^{I} \frac{R_{t}}{(1+r)^{t}}
$$

Based on the theory of capital budgeting, the value of a project can be represented by the net present 
value (NPV) of the incremental free cashes created by this project. The free cash flow is defined as [3]:

Free cash flow

$=$ Earning before interest and taxes (EBIT)

- Cash taxes on EBIT + Incremental accrued taxes

+ Depreciation - Capital expenditures

- Incremental operating working capital

Without loss of generality, it is assumed that $T$ is an integer and

$$
M F_{t}=M F_{0}+P_{t} \times Q_{t}
$$

where $M F_{0}$ is a constant, and $P_{t}$ is the MF per handling unit of year $t$. If $M F_{t}$ does not depend on the volume of cargo, is equal to 0 . To simplify, it is also assumed that there are no side effects on the other revenues of the harbor bureau and no accrued taxes. Because harbor bureau does not have to pay income tax, and because there is no reason to believe that depreciations, incremental working capitals and additional capital expenditures are different in different BL contracts and in traditional contracts, within these $T$ periods, the annual free cash flow coming from a BL contract can be expressed as follows:

Free cash flow $_{t}$

$=\operatorname{Rental}_{t}$

- Amortization of facilities construction $\operatorname{cost}_{t}$

$+M F_{t}$

$=R_{t}-R_{t}+M F_{t}$

$=M F_{t}$

$=M F_{0}+P_{t} \times Q_{t}$

for all $t=1,2, \ldots, T$, where $\left(\right.$ rental $_{t}$ - amortization of facilities construction cost $t_{t}$ ) is considered as the EBIT of this contract. Hence, the value of this contract can be determined by calculating the Net Present value (NPV) of $M F_{t}$. That is, NPVMF

$$
N P V M F=\sum_{t=1}^{I} \frac{M F_{0}}{\left(1+r_{f}\right)^{t}}+\sum_{t=1}^{I} \frac{E\left(P_{t} \times Q_{t}\right)}{\left(1+r_{p}\right)^{t}}
$$

$$
=M F_{0} \times \frac{1}{r_{f}}\left[1-\frac{1}{\left(1+r_{f}\right)^{T}}\right]+\sum_{t=1}^{T} \frac{E\left(P_{t} \times Q_{t}\right)}{\left(1+r_{p}\right)^{t}}
$$

where $r_{f}$ is the risk-free interest rate with constant $M F_{0}$, is an appropriate risky interest rate depending on the intrinsic risk of $P_{t} \times Q_{t}$ [9], and $E(\bullet)$ is the notation of expectation operation.

In a BL contract with $G V$, let be the $G V_{t}$ of the year $t$, then the free cash flow of the year $t$ becomes:

$$
\begin{aligned}
& \text { Free cash flow } \\
& =\max \left\{M F_{t}, G V_{t} \times P_{t}\right\} \\
& =\max \left\{M F_{0}+P_{t} \times Q, G V_{t} \times P_{t}\right\} \\
& =M F_{0}+\max \left\{0,\left(G V_{t}-Q_{t}\right) \times P_{t}-M F_{0}\right\}
\end{aligned}
$$

which is different from equation (4).

\section{REAL OPTIONS}

Since $\mathrm{GV}$ in a BL contract reduces the contract risk involved by harbor bureau, the traditional discounted cash flow (DCF) approaches to the appraisal of capital investment project, such as equation (4), can not properly capture the characteristics of this problem. GV gives harbor bureau the right to "sell" the annual $\mathrm{MFt}$ and receive the guaranteed revenue of $G V_{t} \times P_{t}$. If $M F_{t}$ is greater than $G V_{t} \times P_{t}$, the value of $\mathrm{GV}$ would be worthless and harbor bureau has the same annual payments whether they have BL contract with or without $\mathrm{GV}$. Otherwise it would be worthy of $G V_{t} \times P_{t}-M F_{t}$ which is greater than 0 . So the value provided by GV would be positive. Hence,

The value of BL contract with GV

$=$ Value of $\mathrm{BL}$ contract without $\mathrm{GV}$

+ Value of GV

Several techniques are available for evaluating the value of GV. They are, for example, NPV, Decision Tree Analysis (DTA), Real Options Analysis (ROA), etc. However, Copeland and Antikarov [4] considered that NPV can not capture the value of flexibility in management. McDonald and Siegel [8] and Trigeorgis [13] showed their examples that NPV rule always underestimates the value of investment projects when they involve managerial flexibility. Trigeorgis also mentioned that DTA rule could not adjust the discount rate 
to reflect the change of risk in projects. Unlike NPV and DTA, real options analysis (ROA) can be stated that the value of the project resulting from ROA already includes the value of option due to uncertainty and flexibility in management.

ROA is a systematic and integrated decision analysis process used to evaluate the investment project with managerial flexibility. It is the technique that extends from the financial option theory, which is adopted in the stock market, to be applied in real investment.

Currently, ROA is already accepted as an evaluation process for project under uncertainty in various fields. For example, Pichayapan, Kishi, Hino and Satoh [11] used ROA to evaluate the expressway projects in Hokkaido, Japan. McCormeck and Sick [7] adopted ROA for valuing undeveloped reserves in oil and gas industry. Yamagushi, Takezawa and Sumita [14] used ROA to analyze the land development in Tokyo. Concas, Glaesel, Reich and Yelds [2] valued the economic impact of transportation research activities using ROA approach. Brand, Mehndiratta and Parody [1] used ROA to analyze the risk in transportation planning.

However, there has been a lack of study applying ROA in the port planning and management field yet. On the other hand, researches on the problem of pricing MF or related port facilities have not found either except the fact that the formula of DCF has always been used by harbor bureaus to evaluate various projects in practice. Because that when GV exists in a BL contract, the annual cash flows and its risk, and therefore its discount rate of this contract will be different from that of a traditional contract. These changes can not be reflected in the traditional DCF and DTA methods. Real option method considers the changes of annual cash flows in its cash flow equation (6), and uses the risk-free rate of returns as its discount rate to solve the problem of changing discount rates.

By means of real options, a value is assigned to the options at the management's disposal, GV. This GV value can be determined in a manner that is similar to the valuation techniques for financial options. A summary of the models for option valuation is described by Mun [10]. The real option problem can be solved by solving the partial differential equation (for example, the Black and Scholes model), by dynamic programming (for example, the binomial option model) or by simulation (for example, Monte Carlo simulation). As a general rule, binomial trees are frequently applied in real option valuation, as they allow simultaneous valuation of various options and put less restrictions on the distribution of the underlying value [6].

\section{DETERMINATION OF MF IN A BL CONTRACT WITH GV}

In the problem of $\mathrm{GV}$ evaluation, usually the annual unit MF, $P_{t}$, is taken as a constant in the whole contract period, that is, $P_{t}=P_{0}$, for all $\mathrm{t}$ in the contract period. Because $G V_{t}$ in BL contract is irrecoverable and is known at the beginning of the contract, and the exercise price of the put harbor bureau obtained is fixed, the value of $G V_{t}$ can be evaluated by European put formula [13]:

$$
\begin{aligned}
& p(S, t) \\
& =X e^{-r_{f}^{t} N\left(-d_{2}\right)-S N\left(-d_{1}\right)} \\
& d_{1}=\frac{\ln \frac{S}{X}+\left(r+\frac{\sigma}{2}\right) t}{\sigma \sqrt{t}}, d_{2}=d_{1}-\sigma \sqrt{t}
\end{aligned}
$$

where

$p=$ price of the put

$S=$ price of underlying asset

$X=$ exercise price

$r_{f}=$ risk-free interest rate

$t=$ time to maturity of the option in years

$\sigma=$ standard deviation of the annualized continuously compounded rate of return on the underlying asset

$\ln =$ natural logarithm

$e=$ the base of the natural log function

$N(d)=$ the probability that a value draw randomly from a standard normal distribution will less than $d$

In the case of $\mathrm{GV}$ valuation problem,

$p=$ value of $G V_{t}$

$S=Q_{0} \times P_{0}$

$=$ the facilities rent at the point of time when the contract is arranged

$X=G V_{t} \times P_{0}$

$r_{f}=\ln (1+$ the average annual interest rated of bank loan)

$t=$ time to the evaluated years

$\sigma=$ standard deviation of the annualized continuously compounded rate of return on that can be calculated by:

$$
\sigma=\ln (u)
$$

Let $s p$ be the NPV of GV, it is the value that the lessee offers to harbor bureau and is fair to be paid to the lessee by harbor bureau. Hence the NPV of MF to harbor bureau in a BL contract with GV should be equal to NPVMF - sp, say $v$. Let $p^{*}$ be the unit MF in a BL contract with $\mathrm{GV}$, the following two formulas can be 
obtained:

\section{Formula 1.}

The unit MF in a BL contract with GV

$$
P^{*}=\frac{v}{A+B-C}
$$

where

$$
\begin{aligned}
& A=\left[\sum_{t=1}^{T}\left(\frac{G V_{t}}{\left(1+r_{f}\right)^{t}}\right)\right], \\
& B=\sum_{t=1}^{T} Q_{0} \times N\left(d_{1}\right), \\
& C=\sum_{t=1}^{T} G V_{t} \times e^{-r^{\prime} f^{t}} N\left(d_{2}\right) \cdot \text { and }, \\
& r_{f}^{\prime}=\ln \left(1+r_{f}\right),
\end{aligned}
$$

makes the value of MF in the BL contract equal to $v$ with annual $G V_{t}$ and a geometric operation quantity $Q_{t}$ having a value $Q_{0}$, at the beginning of contract period with an up movement factor $u>1$.

Proof. Because of the requirement of annual $G V_{t}$, the annual MF can be written as

$$
\begin{aligned}
& \operatorname{Max}\left\{G V_{t} \times P^{*}, Q_{t} \times P^{*}\right\} \\
& =G V_{t} \times P^{*}+\operatorname{Max}\left\{0, Q_{t} \times P^{*}-G V_{t} \times P^{*}\right\} \\
& t=1,2, \ldots, T .
\end{aligned}
$$

The first term in the right-hand side of the above equation stipulated at the beginning of the contract period should be treated as a riskless asset. Its NPV can be computed as follows:

$$
\begin{aligned}
& \operatorname{NPV}\left(G V_{t} \times P^{*}\right) \\
& =\frac{G V_{t} \times P^{*}}{\left(1+r_{f}\right)^{t}} .
\end{aligned}
$$

The second term can be treated as a call option with underlying asset $Q_{t} \times P^{*}$ and exercise price $G V_{t} \times$ $P^{*}$, under the assumptions of $Q_{t}$ having a value $Q_{0}$ at the beginning of contract period with an up movement factor $u>1$. This term can be evaluated by BlackScholes' European call option formula as follows: [13]

$$
\begin{aligned}
C_{t} & =\text { value of } \operatorname{Max}\left\{0, Q_{t} \times P^{*}-G V_{t} \times P^{*}\right\} \\
& =S N\left(d_{1}\right)-X e^{-r^{\prime} f^{t}} N\left(d_{2}\right)
\end{aligned}
$$

where

$$
\begin{aligned}
& S=Q_{0} \times P^{*} \\
& X=G V_{t} \times P^{*} \\
& d_{1}=\frac{\ln \frac{Q_{0}}{G V_{t}}+\left(r^{\prime} f+\frac{\sigma^{2}}{2}\right) t}{\sigma \sqrt{t}} \\
& d_{2}=d_{1}-\sigma \sqrt{t} \\
& \sigma=\text { standard deviation of the annualized continu- } \\
& \text { ously compounded rate of return on } Q_{t} \times P^{*} \\
& \text { that can be calculated by } \sigma=\ln (u) \\
& r_{f}^{\prime}=\ln \left(1+r_{f}\right) \\
& N(d)=\text { the probability that a random draw from a } \\
& d
\end{aligned}
$$

Therefore,

$$
\begin{aligned}
\nu & =\sum_{t=1}^{T} \operatorname{Max}\left\{G V_{t} \times P^{*}, Q_{t} \times P^{*}\right\} \\
& =\sum_{t=1}^{T} \frac{G V_{t} P^{*}}{\left(1+r_{f}\right)^{t}}+\sum_{t=1}^{T}\left(Q_{0} \times P^{*}\right) N\left(d_{1}\right) \\
& -\sum_{t=1}^{T} G V_{t} \times P^{*} \times e^{-r^{\prime} f}{ }^{t} N\left(d_{2}\right) \\
& =P^{*} \times(A+B-C)
\end{aligned}
$$

where

$$
\begin{aligned}
& A=\left[\sum_{t=1}^{T}\left(\frac{G V_{t}}{\left(1+r_{f}\right)^{t}}\right)\right], \\
& B=\sum_{t=1}^{T} Q_{0} \times N\left(d_{1}\right), \text { and } \\
& C=\sum_{t=1}^{T} G V_{t} \times e^{-r^{\prime} f^{t}} N\left(d_{2}\right) .
\end{aligned}
$$

This implies that

$$
P^{*}=\frac{v}{A+B-C} \text { Q.E.D. }
$$

\section{Formula 2.}

Under the same assumptions made in Formula 1, the following result can be derived: 


$$
M F D=\frac{P^{*}}{P_{0}}
$$

\section{A CASE STUDY}

To demonstrate the method proposed in the above section, a real case of contract concluded by a shipping company, say Company A, and Taichung Harbor Bureau on July 1, 2000 is provided below. [12] Currently, the facilities' charge calculation method used by Taichung Harbor Bureau is arbitrary. That is, there exists no rule to determine how large the MFD should be offered to the facilities lessee when a contract includes a GV agreement. Hence, instead of presenting the complete contents of the contract, only the basic information related to the evaluation of the value of $\mathrm{GV}$ is described.

In this contract, it was arranged that Company A was responsible for building facilities, composed of a wharf, three silos, road, and digging a water way. Their costs were NT\$300,000 thousands, NT\$941,170 thousands, NT\$ 13,667 thousands, and NT\$ 84,000 thousands, respectively. The total construction cost is NT\$ 1,338,837 thousands. The items of annual lease payments are listed in Table 2 .

The total annual lease payment was NT\$197,919 thousands. It was estimated that the first year operation quantity would be 1,000,000 tons and $\mathrm{GV}$ was also $1,000,000$ tons. The unit price of MF was NT\$ 37 per ton in the contracts without GV. Both parties agreed that the discounted rate of harbor bureau was $8 \%$, the cost of capital for Company A was $10 \%$ and the unit price was fixed in the contract period.

Based on the procedure proposed in previous section, it is necessary to calculate the contract period, $T$, by equation (1) and estimate the volatility of annual operation quantity, $Q_{t}$. In this case, $C_{0}=\mathrm{NT} \$ 1,338,837$ thousands, $R_{t}=$ NT $\$ 197,919$ Thousands, and $r=10 \%$. By solving equation (1), $T=11.8$ years is obtained.

Suppose that Company A and Taichung Harbor Bureau agreed that the operation quantity model can be

Table 2. Annual lease payments included in the case study BL contract

\begin{tabular}{lc} 
Rent of wharf & NT\$ 30,000 (thousands) \\
Rent of silos & 94,117 \\
Rent of road built & 1,367 \\
Rent of land & 8,495 \\
Maintenance expenses & 35,211 \\
Insurance expenses & 13,209 \\
Other expenses & 15,520 \\
Total & NT\$ 197,919 (thousands) \\
\hline
\end{tabular}

Source: A BL contract concluded by Company A and Taichung Harbor Bureau, 2000. represented by

$$
E\left(Q_{t}\right)=Q_{t-1} e^{r Q_{t}}
$$

and also suppose that both parties agreed that the operation quantities are expected to grow on average at a constant rate of $6 \%$ and with $95 \%$ confidence, the actual operation quantity would not be below the current level for the next 11.8 years. Based on these estimates the value of the operation quantity volatility can be derived by the following equation:

$$
\hat{\sigma}=\frac{\sum_{i=1}^{T} \hat{\rho}_{i}-\ln \left(\frac{Q_{T}^{\text {lower }}}{Q_{0}}\right)}{2 \sqrt{T}}
$$

where $\hat{\rho}_{i}, i=1,2, \ldots, T$, are the expected growth rates, and $Q_{t}^{\text {lower }}$ is the lower $95^{\text {th }}$ percentile value of $Q_{t}$. Substituting the above estimates into equation (13), we have

$$
\hat{\sigma}=\frac{10.8 \times 0.06-\ln \frac{1000000}{1000000}}{2 \sqrt{10.8}}=0.099
$$

If the average risk-free interest rate is $5 \%$, then $r^{\prime} f=$ 0.049. Substituting these parameters to equation (8), we obtain the annual present values of $\mathrm{GV}$ for the next 11.8 years listed in Table 3 .

The total present value of GV in this contract, $s p$, is NT\$ 6,838 thousands. It is noted that the value almost comes from the first year. This fact can be easily realized because, when the time passes, the operation quantity is expected to increase so that the probability that operation quantity less than the level of GV becomes very small.

On the other hand, the value, $c$, is increasing when the time interval becomes longer and longer. The total amount $B-C$ is NT\$ 3,410 thousands. The value of $A$ is equal to NT $\$ 8,729$ thousands. The NPVMF of this contract is NT\$347,390 thousands calculated by equation (5) if $\mathrm{GV}$ agreement was not contained in this contract. Subtracting $s p$ from this value, $v=$ NT\$ 340,550 thousands is obtained. Hence,

$$
P^{*}=\frac{v}{A+B-C}=28.1(\mathrm{NT} \$)
$$

and

$$
\mathrm{MFD}=28.1 / 37=0.76
$$

\section{CONCLUSION}

The disputes between port facilities lessees and four harbor bureaus in Taiwan with respect to MF in the 
Table 3. Annual NPV of GV

\begin{tabular}{cccccccccccccc}
\hline$t$ & 1 & 2 & 3 & 4 & 5 & 6 & 7 & 8 & 9 & 10 & 11 & 11.8 & total \\
\hline$d_{1}$ & 0.50 & 1.14 & 1.56 & 1.90 & 2.19 & 2.45 & 2.69 & 2.90 & 3.10 & 3.29 & 3.46 & 3.61 & \\
$d_{2}$ & 0.00 & 1.00 & 1.39 & 1.70 & 1.97 & 2.21 & 2.43 & 2.62 & 2.8 & 2.97 & 3.13 & 3.27 & \\
$p$ & 6197.5 & 333 & 151.7 & 81.4 & 33.3 & 33.3 & 2.96 & 1.48 & 1.48 & 1.48 & 0.37 & 0.37 & 6838 \\
$c$ & 215 & 112 & 151 & 189 & 226 & 262 & 297 & 331 & 363 & 392 & 422 & 450 & 3410 \\
\hline
\end{tabular}

BL contracts with GV have been prevailing for a long time. Although this issue has been discussed for long time, the resolution to the problem has not been found yet. In this paper, real options approach was used to analyze the problem and a procedure was proposed to evaluate MF in BL contracts with GV. The first step in the procedure is to evaluate the value of MF and NPVMF in the contract by the traditional discounted cash flow method as if it was a BL contract without GV. After that, the property of GV was analyzed and found that GV offered by the lessee to harbor bureau resembles the fact that harbor bureau gets a put option from facilities lessee. Hence, it is suitable to use Black-Scholes put formula to evaluate the value of GV, $s p$. Moreover, the value of a $\mathrm{BL}$ contract with $\mathrm{GV}$ should be equal to NPVMF - sp.

Next, it was pointed out that the cash flows in a BL contract with GV is the same as the cash flows that could be gotten from buying a constant annuities and a call option. In this point of view, Black-Scholes call formula was applied, and the calculation formulas of $P^{*}$ and MFD were derived.

Finally, a real case of contract was investigated and its MF was calculated using the proposed method. It was found that the final MF calculated by Formula 1 was NT\$ 28.1 per ton, which is only 76 percent of the original MF of NT\$ 37 per ton.

The real options method applies financial options theory to quantify the value of management flexibility under the condition of uncertainty. This method was applied in various fields successfully. In this paper an academic reasoning why this method can be applied to pricing MF for a BL contract with GV was explained and the pricing formula based on this method was successfully derived.

\section{REFERENCES}

1. Brand, F., Mehndiratta, S.R., and Parody, T.E., Options Approach to Risk Analysis in Transportation Planning (Transportation Research Record 1706), TBR, National Research Council, Washington, DC (2000).
2. Concas, S., Glaesel, T., Reich, S.L., and Yelds, A.T., Valuing the Economic Impact of Transportation Research Activities Using a Real Options Approach (TRB 2003 Annual Meeting CD-ROM), TRB, National Research Council, Washington, DC (2003).

3. Copeland, T., "Valuation in Practice," Recent Trends in Valuation, John Wiley and Sons, New York, pp. 35-81 (2003).

4. Copeland, T. and Antikarov, V., Real Options, Texere Publishing, New York (2001).

5. Kaohsiung Harbor Bureau, 2003 Statistical Abstract, Kaohsiung, Taiwan (2003).

6. Keelung Harbor Bureau, 2003 Statistical Abstract, Keelung, Taiwan (2003).

7. McCormack, J. and Sick, G., "Valuing PUD Reserves: A Practical Application of Real Option Technique," $J$. Appl. Corpor. Financ., Vol. 13, No. 4, pp. 8-13 (2001).

8. McDonald, R. and Siegel, D., "Option Pricing when the Underlying Asset Earns a Below Equilibrium Rate of Return: A Note," J. Financ., Vol. 39, No. 1, pp. 261-265 (1984).

9. Megginson, W.L., Corporate Finance Theory, AddisonWesley Publishing, MS (1997).

10. Mun, J., Real Options Analysis: Tools and Techniques for Valuing Strategic Investments and Decisions, John Wiley and Sons, Hoboken, NJ (2002).

11. Pichayapan, P., Hino, S., Kishi, K., and Satoh, K., "Real Option Analysis (ROA) in Evaluation of Expressway Projects Under Uncertainties," J. East. Asia Soc. Transp. Stud., Vol. 5, No. 2, pp. 3015-3030 (2003).

12. Taichung Harbor Bureau, 2003 Statistical Abstract, Taichung, Taiwan (2003).

13. Trigeorgis, L., Real Options: Managerial Flexibility and Strategy in Resource Allocation, The MIT Press, Cambridge (2002).

14. Yamagushi, H., Takezawa, N., and Sumita, U., "The Real Option Premium in Japanese Land Prices," Proceeding $4^{\text {th }}$ Annual Real Options Conference, University of Cambridge (2000). 